\title{
Estrategias de diálogo y negociación de madres jóvenes para finalizar sus estudios profesionales
}

\section{Strategies for dialogue and negotiation of young mothers to finish their professional studies}

\section{Estratégias de diálogo e negociação de mães jovens para terminar seus estudos profissionais}

\author{
Sara Aliria Jiménez García' \\ Universidad de Colima, Profesora Investigadora de la Facultad de Pedagogía
}

"La felicidad no es algo prefabricado, viene de tus pro-

pias acciones."

(Dalai Lama).

Resumen: El objetivo de esta investigación fue recuperar las estrategias de diálogo y negociación que usaron nueve madres adolescentes y jóvenes para continuar formándose profesionalmente, criar a sus hijos y reconfigurar sus estructuras familiares. Se hicieron dos grupos de discusión al respecto y los resultados revelan que las jóvenes que se embarazaron entre los 16 y 21 años, finalizaron su carrera porque aprendieron estrategias de diálogo, de análisis de sus circunstancias y del cálculo económico y cultural que les traería su preparación profesional. Estas estrategias se podrían sistematizar para discutirlas abiertamente en las aulas y saber qué les está pasando en estos procesos. Además, con éstas se podría apoyar y beneficiar a estudiantes que viven situaciones retadoras semejantes.

Palabras clave: Estrategias de diálogo. Madres universitarias. El poder de decidir.

Abstract: The objective of this research was to recover the strategies of dialogue and negotiation that nine adolescent and young mothers used to continue to train professionally, raise their children and reconfigure their family structures. There were two discussion groups about the strategies that young women used to combine their role as moms and students. The results reveal that young women

Doctora em educação pela Universidad de Guadalajara, México; Mestre em educação pela Universidad de Aguascalientes, México. 
who became pregnant between the ages of 16 and 21 ended their careers because they learned strategies of dialogue, of analysis of their circumstances and of the economic and cultural calculation that their professional training would bring them. These strategies could be systematized to discuss them openly in the classroom, to know what is happening to them in these processes. In addition to these, students who experience similar challenging situations could be supported and benefited.

Keywords: Dialog strategies. University mothers. The power to decide.

Resumo: O objetivo da pesquisa foi recuperar as estratégias de diálogo e negociação utilizadas por nove mães jovens e adolescentes em quanto elas eram formadas como pedagogas, criaram seus filhos e modificaram suas estruturas familiares. Dois grupos de discussão foram feitos em torno ao papel das mulheres jovens como mães e estudantes. Os resultados revelam que as estudantes que ficaram gravidas entre os 16 e os 21 anos, aprendem estratégias de análise de suas circunstâncias e da inversão econômica e cultural referidas a sua formação, e também estratégias de diálogo mais eficazes. Essas estratégias podem ser sistematizadas para ser analisadas e discutidas na sala de aula, com o proposito de conhecer mais sobre o que acontece com estudantes como elas. Além disso, a sistematização e discussão poderiam apoiar melhor às estudantes em situações desafiadores semelhantes.

Palavras-chave: Estratégias de diálogo. Mães universitárias. O poder de decidir.

\section{ACERCAMIENTO TEÓRICO Y METODOLÓGICO}

Ante la crisis humanitaria y económica mundial y actual, diversos organismos recomiendan estrategias para reactivar los mercados laborales y financieros, por ejemplo, el diagnóstico laboral y económico de la ORGANISATION FOR ECONOMIC CO-OPERATION AND DEVELOPMENT (2016) señala que los jóvenes de entre 17 y 29 años pertenecen a uno de los grupos etarios más golpeados por la gran recesión mundial de la última década. Además, en 2015 en México, de la población de 15 años o más, el 36\% 
se encontraba en rezago educativo (INEGI, 2015). Y en Colima este año, de cada 10 personas económicamente activa, sólo 4 eran mujeres (SECRETARÍA DE TRABAJO Y PREVISIÓN SOCIAL, 2018).

De acuerdo con estos retos, diversos organismos planean cómo incorporar a quienes se involucran menos en estos espacios, por lo que parece preciso comprender las condiciones de inequidad que han empeorado la situación; al respecto ILO (INTERNATIONAL LABOUR ORGANIZATION, 2012) comparó datos de hombres y mujeres en el mundo, entre 2002 y 2012 y encontró que las mujeres jóvenes son las más vulnerables en el sector económico, porque mientras se dedican más al cuidado de sus hijos y la limpieza del hogar, tienden a ubicarse en la pobreza, el desempleo y en empleos con menos sueldos y prestaciones.

Es de este grupo minoritario del que hablo en el texto, de nueve madres jóvenes y adolescentes que en lugar de ser desertoras, se quedaron en la Facultad de Pedagogía de la Universidad de Colima, se responsabilizaron de sus hijos, terminaron sus estudios y ahora están en el campo laboral para continuar su camino y en búsqueda de su independencia económica y su desarrollo profesional y familiar.

Inicialmente mi propuesta de trabajo con las mamás adolescentes y jóvenes tenía como propósito que me ayudaran a entender mejor cómo prevenir los embarazos en nuestra escuela, pues cada generación de la Licenciatura en Pedagogía empieza con una población escolar que en su mayoría son mujeres jóvenes y casi todas sin hijos; y a medida que avanzan en sus estudios, algunas se embarazan, por lo que el último semestre (octavo) tiene el mayor número de madres adolescentes y jóvenes. Sin embargo, cuando les pregunté al respecto, observé que tenían muchos más saberes y comprensiones y que a pesar de su preocupación de madres primerizas, habían reorganizado sus dinámicas de vida y estaban dispuestas a compartir sus experiencias.

Además, ubiqué que entre los problemas con los que las mamás se encuentran es que en la escuela no se han construido procesos y estrategias eficientes que las apoyen cuando se embarazan, no están preparadas para ser madres y la vida se les vuelve un caos porque tienen muchas responsabilidades 
y a la vez una mayor urgencia para concluir la escuela. Este conjunto de elementos conllevaría que tengan menores posibilidades de independencia, profesionalización y participación calificada en el campo laboral.

De acuerdo con lo anterior, el objetivo de esta investigación fue recuperar las estrategias de diálogo y negociación que usaron nueve madres adolescentes y jóvenes para continuar formándose profesionalmente, criar a sus hijos y reconfigurar sus estructuras familiares, pues es frecuente que abandonen la escuela, críen solas a sus hijos, o bien, les tome mucho más tiempo finalizar la carrera y requieran hacer negociaciones que a veces desfavorecen su crecimiento profesional y personal, como veremos en el apartado de resultados.

En coincidencia con lo anterior, se aprovecharon recursos interpretativos de la sociología cultural, para configurar el acercamiento teórico del tema, pues según Lan (2010), aunque parece un asunto privado y familiar, el cuidado de los hijos es un asunto cultural y de formación pública que implica comprender las emociones, gastos, trabajo y negociaciones que lo propician.

Las estrategias de diálogo y negociación se entienden como los razonamientos y análisis que usaron las mamás para finalizar su carrera, mientras se hacían cargo de sus embarazos e hijos y reconfiguraban sus relaciones familiares; especialmente se ubican los cálculos económicos y culturales que señalan que les traería su preparación profesional al incorporarse al campo laboral y al hacerse cargo de llevar adelante una nueva vida. En concordancia con Hall, Grindstaff y Lo (2010), las circunstancias culturales que entrelazan las vidas de los participantes de las aulas con sus trayectos familiares, permiten atraer a la escuela las reflexiones que construyen en estos procesos, porque favorecen ambos contextos, sus diálogos y los cambios necesarios en las familias.

Los embarazos inesperados en la adolescencia y la juventud implicaron que las mamás y sus familias participaran en un espiral de aprendizaje acelerado desde que supieron que las primeras estaban embarazadas, de manera que mientras avanzaba el proceso de gestación, cursaban la preparatoria o la licenciatura y el bebé gateaba o corría, fue preciso que dialogaran tanto con su pareja como con sus familias, porque las mamás tendrían que decidir si abandonaban la escuela, ubicar si los demás las apoyarían en este reto y desde 
qué rol participarían, por lo que unos como los otros eran parte de un arduo proceso de comprensión de las nuevas circunstancias de vida a las que se encontraban asociados.

Sistematizar estas estrategias permite observar cómo se experimentan situaciones retadoras y a la vez se propician diálogos y acuerdos que evitan rupturas y conflictos entre los que están alrededor de los bebés y sus jóvenes madres; al mismo tiempo, es posible que retomemos estos diálogos en las escuelas, pues ayudarían a que más mamás terminen sus estudios y críen a sus hijos con menos dificultades emocionales, prácticas y escolares. En coincidencia con Popkewitz (2012), en las necesidades y problemáticas de los participantes de la escuela, podemos ubicar sus racionalidades, los valores y las costumbres con las que éstos producen cambios sociales.

Las estrategias que se pueden observar en los resultados de este texto son tres, la primera consiste en la negociación y las razones de las mamás para no renunciar a sus hijos ni a profesionalizarse; una posición para generar acuerdos y alianzas que a futuro favorecerían el estatus económico y cultural de las mamás y de sus hijos y que rompe con los moldes familiares que implican que ante un embarazo inesperado, éstas abandonen la escuela, sean amas de casa o combinen el cuidado de sus hijos con empleos no profesionales y vivan en la pobreza. Como refieren Crompton y Lyonette (2005) y Lan (2010), en las familias, las mujeres son las que tienen como destino natural e indiscutible ser cuidadoras de los demás.

Las segundas estrategias de diálogo que usaron las jóvenes consiste en tomar el poder de ser madres y estudiantes solas o acompañadas, pues cuando tuvieron la encrucijada de decidir entre permanecer con sus parejas o seguir en la escuela y quedarse con sus hijos, pero sin parejas, tuvieron que sopesar las ganancias de cada situación y el valor que tendría a largo plazo ser profesionistas, mamás y esposas. Como veremos en los resultados, tales estrategias no sólo implican a las parejas, pues las familias de éstas también participan en estos procesos y están tentados a ser los que decidan el destino de las jóvenes. De acuerdo con Bourdieu (1999), las contradicciones de la herencia suceden cuando los hijos se revelan y desmienten los proyectos de sus familias. 
Las terceras estrategias de diálogo y cálculos que usaron las mamás les permitieron conciliar con sus familias, las responsabilidades y gastos familiares y escolares, éstas implicaron que las madres repensaran su lugar, estatus y función en ambos contextos, de modo que sopesaron quienes tenían voz, voto y presencia a la hora de delinear y decidir su propio futuro y el de sus hijos, así como el valor que implicaban estas presencias en sus proyectos de vida. Para Hall, Grindstaff y Lo (2010) y Maturana (1994), el poder de decidir por otros crea más intereses y controversias que las propias experiencias por las que atraviesan los participantes de un colectivo.

En coincidencia con el propósito de ubicar las estrategias de diálogo y negociación de las mamás, para desarrollar el acercamiento metodológico de este trabajo, formamos dos grupos de discusión que permitieron relacionar los relatos individuales de manera espontánea y natural sobre un mismo tema, para tratar de integrar la complexidad cultural (HALL; GRINDSTAFF; LO, 2010) que conlleva ser estudiantes de licenciatura y mamás al mismo tiempo y construir estrategias de diálogo y negociación para resistirse a un camino que las llevaría a dejar la escuela, ser amas de casa, sin estudios profesionales y muy probablemente quedarse en la pobreza.

Las participantes de este trabajo fueron nueve madres adolescentes y jóvenes que en 2012 y 2014 cursaban el último semestre de la Licenciatura en Pedagogía (octavo); los grupos de discusión fueron dos, tuvieron una duración de 59 y 65 minutos, uno se realizó en febrero de 2012 y otro en febrero de 2014, en el primero participaron cinco alumnas y en el segundo, cuatro más.

Como recomiendan Pérez y Víquez (2010), las participantes se conocían entre ellas, pues tomaban algunas clases juntas, por lo que dirigían sus intereses a las experiencias que les parecían comunes y significativas. De modo que mi papel de moderadora consistió en ayudar a estas exploraciones y peguntarles sus acuerdos y desacuerdos respecto a lo que inicialmente postulaban como circunstancias particulares.

Así pues, la guía de discusión la conformamos entre Paola y yo, una de las mamás que me orientó y ayudó a acercarme a sus experiencias; esta guía tenía tres temas generales, sus planes de formación y empleo, su 
rol de mamás y sus prospectivas como madres. De manera que los grupos de discusión con las mamás permitieron que el contexto de sus narraciones fueran sus vidas cotidianas y sus experiencias más significativas (ALEXANDER; SMITH, 2010) como mamás y estudiantes. En consecuencia, como resultados de este trabajo fue posible ubicar las aseveraciones que se refieren a las estrategias que usaron las jóvenes para atender estos dos roles y mantenerse en la escuela.

Seguramente el acercamiento a las experiencias de las mamás de este estudio fue más fácil para mí porque fui mamá joven, mi hijo nació cuando yo tenía 19 años y viví algunas de las peripecias y experiencias que refieren las alumnas, por lo que tuve que aprender sobre estas negociaciones y todas las complejidades que conllevan; a la distancia de mis propias circunstancias, asumo que las mamás que participaron en este estudio tomaron buenas decisiones.

Como parte de este acercamiento metodológico, entre las participantes acordamos cuidar el anonimato de sus historias y la confidencialidad de sus identidades, en coincidencia con los criterios de la European Science Foundation (2010), y entre todas tratamos de entender mejor las experiencias que reflejaban, por lo que podían redirigir los temas de discusión, reelaborarlos o mostrar posiciones diversas u opuestas sobre lo que ahí se expresó.

\section{RESULTADOS, QUÉ ESPERAN LAS MAMÁS ADOLESCENTES Y JÓUENES MIENTRAS SE FORMAN}

Como mencioné antes, las protagonistas de este trabajo son nueve mamás adolescentes y jóvenes que cursaban el último (octavo) semestre de la Licenciatura en Pedagogía de la Universidad de Colima en febrero de 2012 y 2014 y participaron en 2 grupos de discusión sobre las estrategias que utilizaban para combinar su rol de madres y de estudiantes.

Es preciso subrayar que los nombres que distinguen a las jóvenes son ficticios; además usé dos tipos de anonimato, en algunos extractos del grupo de discusión señalo un seudónimo para identificar lo que dicen las mamás; 
en otros, sólo etiqueto estos diálogos como anónimos y asigno un número a cada participante, de manera que sea posible diferenciarlas en la lectura y, a la vez, tratar con más cuidado sus reflexiones, agradecer la confianza que tuvieron para contar sus experiencias y evitar juicios sobre sus circunstancias; al contrario, estos relatos permiten aprender sobre sus saberes y los modos en que resuelven sus trayectos de vida y en la escuela.

En el esquema que sigue concentro algunos rasgos de las estudiantes, sin revelar sus identidades e incluyo condiciones del embarazo, sus prevenciones anticonceptivas, características de su familia, economía y en la escuela, para que sea posible observar los retos que las estudiantes tenían de frente al embarazarse, su necesidad de improvisar y de repensarse asociadas a más de una familia, pues tenían que tomar decisiones y encontrar estrategias para ir adelante en la escuela, junto con las vidas que acababan de concebir.

Su presentación inicial de este modo permite presentar algunos extractos de las historias y estrategias que usaron las estudiantes para continuar sus estudios profesionales. Esta narración tiene diversos retos, especialmente se trata de entender los aprendizajes de las madres, sus trayectos profesionales y persistencia en la escuela, sin considerarlas como desvalidas e incapaces de resolver sus propias circunstancias; tal como señala Walters (2010), que previene sobre el estudio de las identidades sexuales y afirma que el desafío analítico está en observar a los actores más allá de sus rasgos nacionales, raciales y sexuales, a través de paradigmas que trasciendan la idea de rescatar a quienes sufren y sufren durante años. 
Esquema 1 - Madres adolescentes, sus hijos y sus relaciones familiares

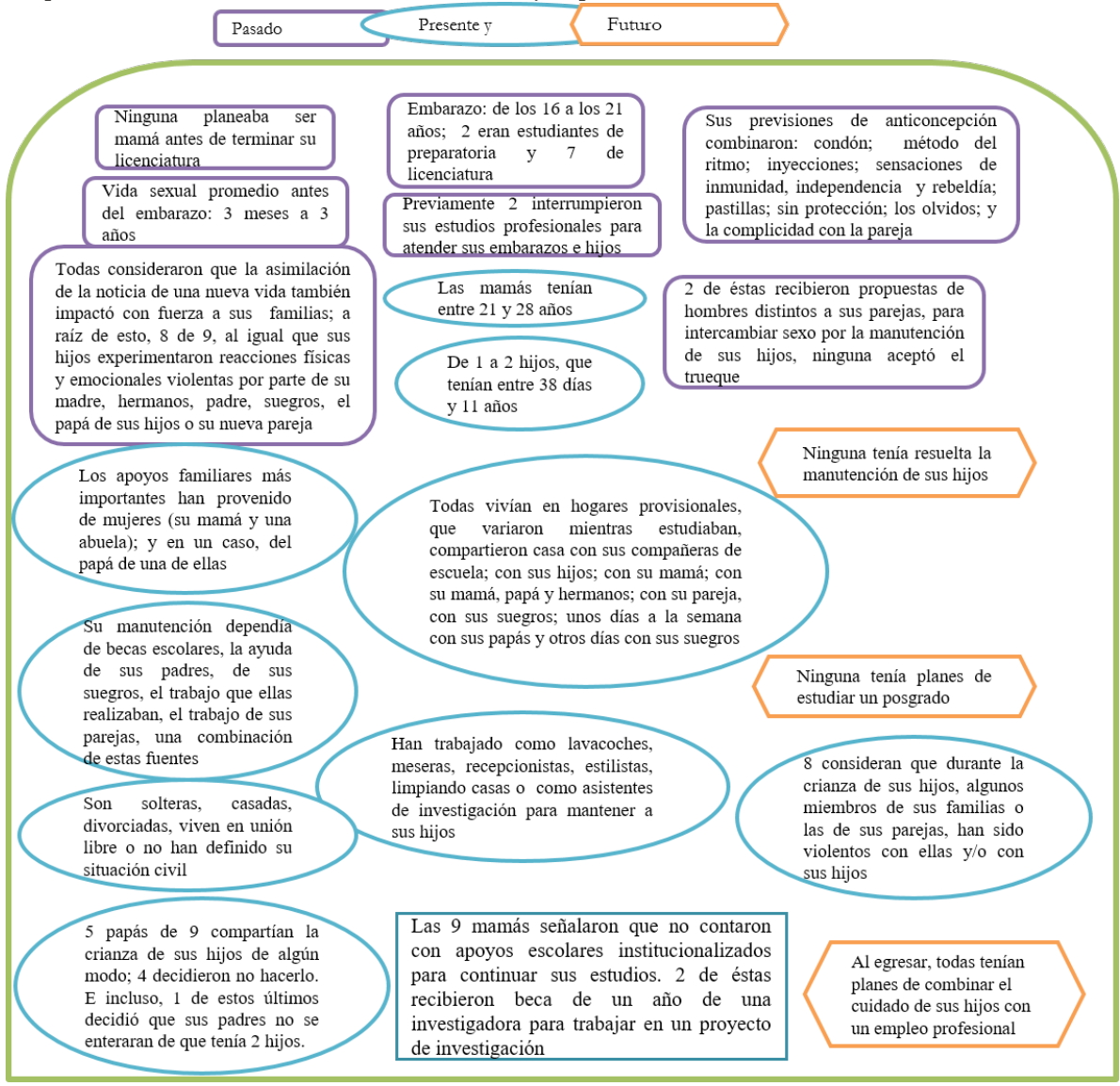

Fuente: el autor.

El conjunto de rasgos del esquema previo refiere que todas las mamás adolescentes confiaban en que sus condiciones de vida y las de sus hijos mejorarían al finalizar la licenciatura, un mérito de los procesos de formación en las universidades, pues sin duda las estudiantes muestran confianza por los cambios que produce la escuela.

También existen aspectos mejorables en la escuela, pues se puede leer la falta de apoyo a las mamás para terminar sus estudios, parecen solas y avanzando con sus recursos y a veces con los de sus familias; al respecto Wong Huerta (2012) señala que el origen en que nace un ser humano, no siempre determina su destino 
y a veces en esta ecuación, la fuerza fundamental de este cambio viene de la preparación, aunque no siempre sea de la que provee el Estado.

De un modo más o a veces menos activo, los participantes de sus familias promocionan la profesionalización de las jóvenes mamás; y a la vez, la formación de las mamás adquiere sentido cuando les permite combinar sus responsabilidades en el aula, con la atención a sus hijos y sus reajustes en las dinámicas de día a día; cuando estas condiciones se juntan, las estudiantes pueden darle un impulso a su rol de cabezas de familia; y, al contrario, cuando no encuentran estrategias y apoyos para vincular estos quehaceres, las mamás luchan contracorriente, como veremos en las partes que siguen en esta narración.

\subsection{ESTRATEGIAS DE NEGOCIACIÓN Y RAZONES DE LAS MAMÁS PARA NO RENUNCIAR A SUS HIJOS NI A PROFESIONALIZARSE}

En un escenario multicultural como el que configuran las universidades, los participantes tienen mucho que enseñar respecto a los modos en que se organizan los procesos educativos, especialmente los modos en que razonan sus circunstancias y que aprenden a negociar su lugar en las escuelas. Para esto Willis (1988) propone que ubiquemos los valores que favorecen a aquellos que superan las barreras sociales y familiares para las que parecían destinados.

Además, al analizar las experiencias de madres jóvenes e inexpertas, es posible reconocer que los hijos son los seres humanos que tienen el lugar más trascendental para que los otros, los nuevos y viejos padres, repiensen sus posiciones en la vida y se pregunten qué es lo más conveniente y cómo hacerlo; entonces, en sus decisiones se entrelazan emociones, razones y tareas que a veces crean nuevas posibilidades para la felicidad, la angustia, el miedo, la alegría, el enojo o la esperanza. Como dice Walters (2010), una formación multicultural implica atraer estos saberes y practicarlos en las aulas.

Los relatos que siguen muestran estas complejidades, en cursivas o itálicas están las razones que propician el diálogo y la negociación de las 
mamás para explicarse qué hacer en momentos decisivos de su embarazo y en la crianza; y cómo hablaron con sus familias respecto al apoyo que requerían y el miedo que experimentaban en el proceso. Además, permiten ubicar los diálogos que podríamos propiciar en las universidades para que el embarazo no llegue antes de lo esperado y, cuando llegue cuenten con algunas estrategias para analizar sus circunstancias y encontrar las vías para combinar tareas de madres y estudiantes.

Estas estrategias implicaron que reconocieran qué les estaba pasando, cómo ser responsables de sus hijos sin abandonar la escuela, y como se puede leer en las siguientes afirmaciones, el embarazo en las jóvenes es una circunstancia cultural que también les provee herramientas analíticas y resolutivas.

Francesca: "Crees que eres inmune, ¿no?, que a ti no te, no te puede pasar." (G1,5, 18).

Alessia: “...y aunque sepas tú de, de los anticonceptivos y eso, como que la rebeldía de no hacerlo, como decir, ay pues no me pasa nada, ya sé, ya sabe uno, ya sabe de todo lo que pasa y que el embarazo y que los, y que las enfermedades y todo eso, pero.... İsí, sí sabe uno, sí sabe, nada más que, que sabiendo uno, al ahí se va!, aún te vale y, y sucede..." (Gl,4,6).

Iliana: "Porque no tienen la culpa de lo que tú haces, o sea igual como, como te pasa, igual tienes que afrontar tu responsabilidad, porque es tu responsabilidad también no haberte cuidado o algo y sabías...entonces pues...ni modo, para mí es una vida desde el momento en el que está ya, es un, es un ser pues." (Gl,9,5).

Anónima 5: "Yo sí pensé en abortar, porque yo decía cómo voy a... toy (sic) en la escuela, este...mis papás, pensaba, ¿qué van a pensar?, que, ¿̇ué van a decir?, porque, pues la, esas veces que, lay mi hija! y toda la confianza y, Iuff, mi hija!, porque pues, nunca he sido mala en la escuela y este...y no, ps (sic), ila más grande!, y..., sí pensé, de hecho hasta tomé, me llegue a tomar unas pastillas y no me sirvieron de nada..." (G1,9,7).

Anónima 3: "en mi caso, o sea que yo respeto mucho la vida hasta en los animales y todo esto, no, no estaba dentro de... de mi código de ética, 
¿no?, yo nunca pensé de abortarlo y sí hubo la propuesta de parte del papá de mi (bebé) y de parte de gente de mi familia, les que aborta!, ino!, ijamás en la vida!, o sea, lyo me aviento!" (G1,10,2).

Como veremos enseguida, las estrategias de diálogo y las razones de las mamás para no renunciar a sus hijos ni a profesionalizarse surgen en medio de una preparación intensiva, que acarrea soluciones concienzudas, crecimientos o a veces conflictos entre las mamás y quienes se sienten autorizados para definir el destino y lugar profesional y personal que corresponde a las jóvenes y a sus hijos, para decidir si deberían seguir embarazadas y en la escuela o deben quedarse en casa. Según Maturana (1994, p. 181), "las experiencias nunca son un problema en el ámbito de la coexistencia humana, es el ámbito de las explicaciones y en el de la utilización de nuestras experiencias en donde podemos entrar en fatales disputas."

Gabriela: "En... en mi casa, no un conflicto este... de familia, siempre ha habido un conflicto entre mi papá y yo, ee... cuando él se enteró, se molestó demasiado, de hecho me dijo que me tenía que juntar o casar, o sea, hacerme responsable de esa manera y yo le dije que mi manera de hacerme responsable era quedándome en la casa, porque si yo me juntaba no iba ni a trabajar ni a seguir estudiando, me iba a tocar ser una ama de casa y yo no quería eso y pues mi decisión era quedarme en la casa y seguir estudiando y ya que terminará mi carrera, me junto y lo que sea, pero ya que tuviera algo como más seguro." (G2,6,6).

Sonia: "Pues cuando yo salí embarazada, fuimos a hablar con mis papás, ya por comodidad mía; mi papá al principio sí era de la idea de que yo me casara, pero pues yo no me iba casar y no porque no lo quisiera, sino porque, para mí no es justo casarse como una obligación por estar, por el hecho de estar embarazada, entonces yo le dije que el día que me case no va ser por eso, sino va a ser porque yo quiera, entonces decidimos que por comodidad me iba a quedar en mi casa, pero él (su pareja) me iba a estar apoyando." (G2,6,15).

Gabriela: ". . lo que sí pasó es que sentí mucha pena con mi mamá, porque ella es la que me apoyaba o me apoya económicamente y sentí mucha 
pena con ella y este... le dije pues, que como ella me había dado la confianza, yo le iba a dar la confianza de decírselo, porque ella se lo... o sea lo merecía, no merecía que yo se lo ocultara y este... fue a la única persona que en cierta manera le tuve miedo, pero no fue miedo, si no fue como vergüenza con ella, este, se lo conté y ella me dijo: no, no, no, no te preocupes..., no te vas a salir de estudiar, ni te vas a ir de la casa, ni nada, tú te vas a quedar aquí y vas a seguir estudiando y ya este... yo le dije pues que sí, que eso era lo que yo quería y pues yo no me quería juntar con él..." (G2,4,11).

Iliana: "Y es que yo tengo mucho sentimiento porque... él papá de mi bebé, pues se vino, él dejo todo...por nosotros y...y ni siquiera vivía yo con él los primeros meses y estaba casada y no vivía con él, y porque aparte mis hermanos me dijeron que...que me daban todo, me pagaban clínica y todo, pero que no me casara." (G1,21,8).

Como se puede leer en las opiniones previas, las madres adolescentes aportan valores, razones y estrategias de negociación que diversifican las tradiciones familiares que antes se habían instituido, las que no siempre recuperan las cosmovisiones del mismo grupo, por lo estas visiones parecen reconstruidas desde otros ámbitos; con suerte las interacciones y aprendizajes en la escuela jugaron a favor de un análisis crítico sobre las ventajas de profesionalizarse a la vez que crían a sus hijos. Como señala Bourdieu (1999), en el ámbito de la familia, pareciera que no hay salida para el heredero, es desmentir o seguir a su padre y a su proyecto y a veces la escuela apoya el proyecto de las familias, pero no siempre.

Aunque no tengo evidencias empíricas de que estos aprendizajes provienen de las escuelas en que se han formado, parece viable que en las aulas se aborden y discutan las razones por las que es necesario que haya democracia e igualdad entre los participantes de una familia, por lo que un embarazo inesperado en la adolescencia y la juventud no constituye una razón suficiente para que las estudiantes pierdan sus derechos a opinar y a decidir sobre su futuro y el de sus hijos.

Estas experiencias pueden propiciar nuevas alianzas y desencuentros en las familias; o bien, contradicciones respecto a los modos de pensar cómo 
se construye y organiza dicha entidad social; en coincidencia con Rodríguez y De Keijzer (2002), a veces las jóvenes no sólo analizan su propio ejercicio como partes de una familia, también revisan el poder que tienen para este ejercicio.

Como reflejan las jóvenes en sus razonamientos y estrategias de negociación para no renunciar a sus hijos ni a profesionalizarse, su trabajo implica dialogar y tener razones que contrarresten las opiniones de algunos padres, hermanos, suegros y parejas que reclaman el derecho a decidir por éstas; recordarles que ellas no son una extensión de los otros, por lo que contradicen a quienes creen ingenuamente que al embarazarse cederán sus capacidades y derechos de madres y de estudiantes. En la parte que sigue se muestran otras evidencias sobre estas estrategias de negociación y diálogo.

\subsection{ESTRATEGIAS PARA TENER EL PODER DE SER MADRES Y ESTUDIANTES SOLAS O ACOMPAÑADAS}

Los familiares que creen que tienen el poder de decidir sobre las madres jóvenes y sus hijos, suponen que a éstas les corresponde ser lo que los demás definan sobre su incierto y frágil futuro, pues ante sus experiencias pasadas requieren correcciones antes de opinar, actuar y volverse a equivocar. Sin embargo, las actitudes firmes de las mamás que se quedaron en la escuela y tuvieron a sus hijos, resultan un contratiempo para los familiares posesivos y controladores.

Estas estrategias que movilizan las mamás que cursan estudios universitarios, ponen en juego sus nociones de lo que construye el poder en las relaciones familiares y sobre quiénes tienen el derecho de velar por éstas y por sus hijos; estas alianzas, disputas y disposiciones cambian, se reorganizan y se vuelven a negociar, mientras las jóvenes persisten en la escuela hasta concluir su carrera profesional.

Al mismo tiempo, en este análisis parece valioso reflexionar, ¿jpor qué algunos de los papás jóvenes no consideran que tienen las mismas responsabilidades de cuidadores de sus hijos que las que tienen las mamás?, 
¿qué valores culturales sobre la crianza discutimos y explicitamos en los procesos de formación en las escuelas y en las familias?

Las mamás no responden del todo a estas preguntas, como veremos en sus afirmaciones, sin embargo, algunas explican su propia visión de cuidadoras, cuando sus parejas se ausentaron, contribuyeron muy poco o alguien más los sustituyó como padres. En consideración a estas experiencias, negociaciones y diálogos, en las escuelas podemos trabajar de manera más explícita y abierta en favor de la igualdad de oportunidades, para que ubiquemos las ventajas del consenso, de las decisiones de pareja en apoyo a la vida de unos y no en demérito de los otros.

Anónima: "Se me cayó el niño al piso de lo cansada que estaba, o sea, gracias a Dios no le paso nada, no, casi lo agarré en la rebotada, pero el regaño de mi papá, el regaño de mi mamá, que no sé qué, que porqué lo dejaste caer. No lo dejé caer, me quedé dormida, ya era un cansancio tan grande y no estaba acostumbrada, pues eres una adolescente que estas impuesta a dormir doce horas, que no tienes responsabilidades." (G1,40,19).

Romina: “¿Qué papel jugo? (Se refiere a su pareja)." (Gl, 18,1 1).

Anónima 9: "iNinguno!" (Gl, 18,12).

Anónima 3: "iPues no, muy cómodo!" (Gl, 18, 15).

Anónima 9: "iPues no juegan!" (Gl, 18, 16).

Anónima 3: "Pues muchos hombres, este...juegan un papel muy cómodo ¿no?, ite embarazo, te sugiero que abortes y pues como no aceptas, pues ese ya es tu pedo!, entonces." (G1,18,17).

Anónima 3: "iDe hecho!" (Gl,18,19). "Sí, o sea, con mi primer embarazo pues fue muy padre, ¿no?, porque él quería ser papá, yo quería ser mamá, estábamos bien mensos, no sabíamos las dimensiones del problema." $(\mathrm{Gl}, 18,20)$.

Anónima 2: "...de mi familia, fue mi mamá la que aceptó que estuviéramos así, en el caso de la familia de él, fue el papá el que aceptó que estuviéramos así; este, mi papá decía, ino, juntos o separados!, y la mamá de él 
también decía, İo se casan o no se queda ella aquí!, y este... bueno, yo siento que, esa parte de decir bueno, yo quiero estar sola en ocasiones, era también por el contexto de vida, porque mi mamá también estuvo sola." (G2, 10,13).

Francesca: "Yo pienso que más bien todo eso, ese asunto recae más que nada como en la cultura, porque siempre, o sea si, si la mujer es la que se embaraza, pues es la que las lleva de perder, entonces tú tienes que buscar la forma de no perder, por así decirlo." (G1,7,14).

Cuando se crean disputas a partir de las nuevas vidas, parece que nadie sale ganando; al contrario, éstas merman la capacidad de independencia de las mamás primerizas en el ámbito escolar, las oportunidades de sus hijos mientras crecen y, a la vez, desorganizan los procesos familiares que originaban armonía y apoyo entre unos y otros.

Las visiones de lucha entre los participantes los desgastan y los hacen verse como contrarios y sin causas comunes; mientras que las posiciones de escuchar y aprender propician el crecimiento colectivo, la persistencia de las mamás en la escuela y favorecen la crianza de los bebés.

Las estrategias de negociación que evitan la lucha implican escuchar y que todos los participantes convivan como iguales, que se beneficien del diálogo y acepten que los demás también son fuentes valiosas de conocimiento, por lo que evaden la frases como, porque lo digo yo o porque yo mando y se acabó; una afirmación que a veces hemos escuchado en los profesores, en los de una escuela lejana, no en la nuestra.

Las estrategias de diálogo que usan las estudiantes para tener el poder de ser madres y estudiantes solas o acompañadas, les crean oportunidades dentro de su familia y en la escuela y les permiten concluir sus estudios con menos angustia y más atención a sus roles de mamás y de estudiantes. Al respecto Crompton y Lyonette (2005) opinan que mientras la igualdad de responsabilidades no se convierta en una intención política explícita en las organizaciones, su aprendizaje pasará desapercibido y quienes más suelen quedarse al margen de estas negociaciones en los ámbitos escolares y laborales, suelen ser las madres, a las que se les reconoce como cuidadoras por naturaleza. 
Todas las mamás que participaron en este estudio tomaron la decisión de quedarse con sus hijos, aun cuando cuatro parejas de éstas cambiaron de parecer sobre su implicación en una vida conjunta y/o dijeron que siempre no estaban listos para vivir el reto; así, las estudiantes mantuvieron su posición de responsabilidad y terminaron sus estudios de licenciatura; aunque parezca que con esta decisión se aventaron un salto triple en un trapecio de circo, pues combinaron las actividades de su hogar con la atención materna y las tareas de la escuela, no obstante que la escuela no está organizada para darles un trato diferenciado y acorde con sus circunstancias de mamás.

Si bien podemos observar un retraso cultural en las familias y en las escuelas respecto a la división de las responsabilidades y oportunidades que conlleva ser madres jóvenes y cursar una carrera, también se puede ver que existe una veta analítica y discursiva poco explorada sobre los beneficios, retos y compromisos que tienen los hombres que sí se inmiscuyen en estos procesos.

Es valioso y necesario que los papás jóvenes participen en la crianza de sus hijos, se requiere desarrollar estrategias de diálogo y negociación para implicarlos, mostrarles estos dilemas y las ganancias que conlleva conocer a sus hijos desde que son pequeños y convivir con ellos, antes de que se acostumbren a vincularse sólo por su consanguinidad y no por la complicidad que se construye en la vida cotidiana de una familia; tal vez las pesadillas de los atormentados padres y madres adolescentes se componen del recuerdo de su ADN caminando por ahí, sin que le conozcan la cara y al mismo tiempo, de la tranquilidad de verse liberados del trabajo y las dificultades que implican la crianza día a día.

Bárbara: "Yo, este, pues mi pareja, este, al principio pues tenía, tenía dieciocho, diecinueve años, quiere hacerse responsable, pero no sabe cómo, ¿verdad?, entonces sí fuimos, platicamos yo y él y dijimos, estamos, este, estamos embarazados, porque los dos estamos embarazados, este, ¿̇ué hacemos?, antes de platicarlo con, con mi familia, ah, ìporque la familia se va meter mucho y va querer decidir por nosotros!, entonces dijo, ¿tú qué quieres?, İyo quiero casarme contigo!, tú, ¿te quieres casar conmigo?, ìpues sí, hay que casarnos!, él fue a hablar con mi mamá (para decirle) que estaba embarazada, 
yo ya estaba embarazada, pues ya tenía cuatro o cinco meses, era una cosa plana, no se me notaba nada, no sé porque, por el miedo, yo creo." (G1,24,4).

"Anónima 6: "Ay pues, el papá de mi (bebé) no sé ni dónde chingados anda, este...pues ya les dije que sí vivíamos juntos, este, estuvimos, fuimos novios como...unos dos años, este vivimos juntos un año y me embaracé y ya nomás, pero nomás (sic) duré como cinco años con él, este, estaba siempre a medias, él siempre estuvo a medias, este vivíamos juntos, pero él quería seguir viviendo como quinceañero, cuando no era quinceañero, es cinco años más grande que yo y este... se iba a tomar, con los amigos ya llegaba, que llegaba a las tres, cinco de la mañana, a veces no venía, a veces llegaba a las doce del día del otro día, o sea, bien feo, este, trabajaba cuando íbamos en la prepa trabajaba, pero este, un día sí, un día no, un día sí, muy inestable..." (G1,25, 14).

Parece que esta facilidad o dificultad de los jóvenes papás para dialogar y comprometerse con las circunstancias que impone la crianza de sus hijos, también se relacionan con las posiciones fijas o flexibles de negociación que toman algunos miembros de las familias de las mamás y los papás jóvenes, pues ante la inesperada situación, éstos sienten la necesidad de protegerlos, para limitar el impacto que tendrán las nuevas circunstancias de su vida; y, a la vez, parece que algunos familiares intentan extremar precauciones para que la experiencia no se repita, por lo que las medidas van desde crear nuevas reglas, sancionar las decisiones que los contraríen y hasta evitar las posibilidades de diálogo. Lo que algunos participantes no se han imaginado es que cuando llegan los bebés a las familias, renuevan sus relaciones, traen alegrías y a veces ponen a los abuelos de cabeza para divertir a sus nietos. En estos movimientos de poder, las mamás aprovechan para aprender y usar estrategias de diálogo y negociación para tomar el poder de ser madres y estudiantes solas o acompañadas.

Anónima 5: "...ya cuando yo ya salí embarazada, pues yo, el primero que supo, pues fue él...y ya lo que había comentado que pasó y después me dijo, no, pues nos vamos a casar, este, fue a pedir mi mano, pero, desde el día que fue a pedir mi mano, ps (sic), eran como quince días para casarnos, entonces decían, ¿por qué tan pronto?, ¿verdad?, ya como que se empezaban a dar color de lo que estaba pasando, de hecho hasta una de mis hermanas 
dice, ite voy a contar los días, los meses!, me dijo, ite voy a contar los meses!, ¿eda? (sic), así como en broma, este, y ya me casé..." (G1,23,1 l).

Anónima 2: ". . cuanto salí embarazada ya no hubo relación (con mi papá), porque él dijo, mientras tu estés aquí, yo no voy a poner ni un pie en la casa y decidió pues, ya no venir y venía, pero como que ya sabía mis horas de que yo no estaba en la casa, iba, comía y se iba, o sea, a mí no, nunca me tocó verlo en él, durante el embarazo." (G2,12,7).

Anónima 2: "Yo le dije a mi mamá que si eso era un problema para ella, pues yo me iba, o sea no había ningún problema y mamá me dijo, pues que no, porque nosotras dos siempre habíamos estado juntas y él (su papá) nunca, él nunca había estado junto con ella, entonces era como, laja, de decidir, voy a escoger entre mi hija y mi esposo, te voy a escoger a ti!, İsiempre vas a ser tu más importante que él!, entonces, este, bueno, fue todo un relajo porque hasta mi hermano se pelió (sic) con mi papá, porque mi papá prácticamente me corrió y mi hermano le dijo, ps (sic) que no, que él viera lo positivo de que yo me quedara en la casa, que era de si, él o sea, mi pareja, un día me dejaba, yo no iba a quedar volando y entonces, si me sacaba de estudiar y la metes así, como decir, a ama de casa, después qué iba a hacer." (G2, 12,14).

Romina: "Los papás ahí andan, felices, viejitos todos y allí andan, uno es quien anda cargando con los niños, o sea, a los papás no les hace uno daño, en ese ratito tal vez, en ese momento sí se decepcionan, se enojan, lloran y te dicen hasta lo que no, pero, ahorita, son abuelitos y son felices y, y a ellos les vale y les da risa, por ejemplo mis papás, mis hijos que ya están grandes, o sea, mis papás a veces este, les digo, lay es que este niño no me hace caso!, İquerías tener hijos!, İasí eras tú y eras peor!" (G1,15,16).

Estas estrategias de diálogo y negociación que usan las mamás para tomar el poder de ser madres y estudiantes solas o acompañadas, también incluyen razones respecto a la igualdad entre las oportunidades y responsabilidades de papás y mamás adolescentes y jóvenes, por lo que parece viable subrayar que cuando las mamás se quedan solas con sus hijos, reflejan que ni mamás ni papás son completamente exitosos o desventurados 
a lo largo de su historia individual y colectiva, pareciera que siempre les falta algo a todos, hijos, padres y madres.

Como es posible notar en las opiniones de las mamás, los actores y sus circunstancias están configurados de una pluralidad enorme, de manera que mientras parece que omitirse de la crianza puede ser ventajoso para unos o en algunos momentos de la vida; la misma condición puede volverse motivo de gran alegría, preocupación y crecimiento para otros participantes.

De acuerdo con estas experiencias y estrategias de diálogo y negociación que usaron las mamás para tomar el poder de ser madres y estudiantes solas o acompañadas, es posible observar que, si bien sus circunstancias como madres y estudiantes son retadoras, no se vencen, van a la escuela, persisten, reflexionan y buscan los medios para culminar su carrera. Al respecto Siegel (2007) se pronuncia por crear miradas analíticas que sean optimistas, que incluyan a los actores en sus diferentes circunstancias y no sólo refieran a quienes están en una de las posiciones que históricamente hemos etiquetado como de desventaja.

\subsection{ESTRATEGIAS DE DIÁLOGO Y CÁLCULOS DE LAS MAMÁS PARA CONCILIAR CON SUS FAMILIAS}

Parece relevante subrayar que en estos procesos en que las mamás crean conciencia sobre las responsabilidades y oportunidades que tienen, los participantes de la escuela podemos observar que ni todo está dicho en la escuela ni las decisiones fundamentales se toman siempre por los que tienen el poder agarrado del mango todos los días, pues estas organizaciones están llenas de rejillas y de vías de desarrollo que los empoderados ni han imaginado.

Así pasa con las mamás jóvenes, cuando ni ellas ni los demás consideraban que el embarazo en esta etapa de la vida construiría oportunidades y prospectivas para su independencia y crecimiento, desarrollaron su derecho a decidir y a equivocarse como madres e incluso, a ser respetadas y a negociar apoyos en la escuela y en las familias. 
Entonces cuando se trata de estrategias de diálogo y cálculos para conciliar las responsabilidades y los gastos familiares y escolares, hay que mirar los vaivenes de la cotidianeidad de las mamás, sus ritmos de aprendizaje, interpretaciones y los saberes que van desarrollando; en coincidencia con Willis (1988), a través de diversas costumbres de interacción, de la fuerza emocional que se imprime en la conversación sobre la división del trabajo, se transfieren formas de conocimiento en uso, a la vez que construyen culturas subyacentes. Y como agrega Mills (1961), el individuo sólo puede comprender su propia experiencia y evaluar su destino localizándose a sí mismo en su época, al captar la historia, la biografía y sus intersecciones dentro de la sociedad.

El trabajo y los esfuerzos de las mamás jóvenes para ser responsabilidades de una nueva vida y continuar con sus estudios profesionales, también implicó que aprendieran que tenían grandes retos por delante y en estas dinámicas comprendieron que su estatus iba cambiando y, por ende, sus posibilidades de tomar decisiones y de repensar quiénes son sus autoridades, quiénes sus pares, qué es lo que pueden aprenderles y qué no están interesadas en considerar; en algunos de estos casos, como veremos en las afirmaciones que siguen, no todos las piensan como pares o como participantes que requieren apoyos adicionales en la escuela y en la familia, para profesionalizarse y encargarse de sus hijos.

Bárbara: "Y energía y, y uno sale temprano, llegas tarde a tu casa, la encuentras toda hecha y si te queda un aliento haces y resulta que todavía los maestros te dejan tarea, ¿de dónde, de dónde quieren que saque fuerza?" $(\mathrm{G} 1,33,17)$.

Paola: "iQue (el doctor) Fernando quiere que leas 272 hojas!" $(\mathrm{Gl}, 33,19)$.

Bárbara "iDe aquí (viernes) al martes, pues no!" (Gl,33,20).

Francesca: "iQue las lea él, dile!" (G1,33,21).

Paola: "Hago todas las cosas para, ni ganas, bien cansada" $(\mathrm{Gl}, 37,16)$.

Bárbara: "Ay encárgate (todas se ríen)" (G1,37,17). 
Alessia: "Pero no me despiertes" (G1,37,18).

Paola: "Luego me hablas cuando acabes, para bañarme" (G1,37,19).

Romina: "Cuando termines me tapas (todas se ríen)" (G1,37,20).

Paola: "Porque hace frío" (G1,37,21).

Francesca: "No, por si el niño viene" (Gl,37,22).

Anónima 2: "...ya después como a la semana... la mamá de él influyo en él y él empezó, ihay que casarnos, hay que casarnos, hay que casarnos, hay que juntarnos!, y yo, o sea, infartada, porque yo le dije, ino! y dije, bueno... y le empecé a explicar, Imira, si nos juntamos, no nomás (sic) es decir vámonos y hay que irnos a vivir en un techo y ya, hay que pagar luz, hay que pagar renta, hay que pagar comida!, lyo no me voy a salir de estudiar!, ly si tú te quieres juntar, tú te tienes que salir de estudiar y yo no lo creo justo!, entonces este, como que reaccionó un poco y me dijo, ibueno pues!, ipero cuando nazca (el bebé), sí hay que juntarnos!, le dije, iah, está bien!, icuando nazca, nos juntamos!..." (G2,8,2).

En este renovado protagonismo que las jóvenes adquieren sobre sus propias decisiones y la afirmación de su identidad como madres y estudiantes universitarias, organizan nuevas metas en la vida y trazan líneas que incluyen a sus hijos, su preparación profesional y su idea de independizarse; aunque estas reconfiguraciones familiares no siempre consideran a sus padres o a sus parejas; al menos no en los términos tradicionales que la hemos concebido históricamente, con una mamá y un papá que se casan y que viven con sus hijos en el mismo techo; o como la hija que no sale de casa de sus padres hasta que cumpla sus designios, pues le temen a lo qué dirá la gente.

En este sentido, Willis (1988) señala que la identidad social no se repetirá en un grupo, si los actores la reforman y aplican a nuevos fines; así podemos participar la escuela, discutiendo costumbres que crean movilidad y adelanto y aquellas que reducen los espacios de interacción para unos cuantos actores.

Paola: "Ajá, por no ayudarme, entonces su mamá me hablaba, me la hacía chillona y toda la cosa y este, pero fíjense, la señora, la señora iba me 
rogaba y me decía, iPaola, por favor!, se me hincaba y yo pues, İseñora, es que, pues él es el que se tiene que hacer responsable, no usted!" (Gl,28,2).

Paola: "Ajá, i̇usted cálmese, aliviánese, déjelo a él que haga sus cosas, si a él le vale, usted déjelo, porque si él no sufre, nunca va a cambiar! y este, ah, pero la señora iba conmigo a llorar, pero iba a ciertos lugares o con personas que nos conocían a juntar firmas para quitarme a (mi bebé)" (G1,28,2).

Romina: "Entonces este... pues yo, yo tomé la decisión de que cuando yo pudiera pagarme mi escuela, yo iba a regresar, no pensé que fuera a pasar tanto tiempo, pensé que era más fácil, o sea, hay pues, trabajo y veo cómo le hago, es muy difícil, pero pues yo ahorita, yo puedo decir, no pues mi mamá ya no me ayuda, o sea en nada, mi papá ya no me ayuda, en nada y lo estoy sacando adelante yo sola" (G1,42,20).

Anónima 7: "Que no me casara con él y mi mamá pues al principio sí, pues qué va decir la gente y este, y él, él se vino y vivía donde trabajaba, porque yo le explicaba lo que estábamos pasando, la verdad no podíamos ni rentar, conforme pasan los meses, pues ya aguantaba más las caras, indirectas en mi casa y este...y me venía a la escuela y yo seguía adelante y a él lo veía cuando salía de trabajar, y...como novios nos veíamos" (G1,21,12).

En este caso, las estrategias de diálogo y cálculos para conciliar las responsabilidades y los gastos familiares y escolares se materializan principalmente en la culminación de las carreras profesionales de las mamás, aunque parece que esto tuvo más que ver con su determinación, trabajo individual y familiar y menos con una estructura organizativa o política que se desarrollara desde la escuela para incentivar su permanencia.

Paola: "Hay un par de becas que me ayudan, este" (G1,44,1). "Bien jodidas, la neta" (G1,44,2).

Romina: "Ya la quisiera, no me la dieron a mí" (Gl,44,3).

Anónima 8: “Yo, pues este, mi (bebé) depende también de su papá, pero pues este, también en mi casa me apoyan, me dan dinero para mí y para así que, como dice ella, comprar pañales o la leche." (Gl,46,5). 
Anónima 2: "Bueno, en mi caso este... mi mamá es la que la que me apoya económicamente, al igual mi hermano; él (mi pareja) trabaja con sus papás, pero solamente los fines de semana, o cuando hay vacaciones, trabaja en las vacaciones con su papá o se mete a trabajar este, en cualquier lado" (G2, 14,9).

Además, en el ámbito privado de las jóvenes mamás, también se pueden observar señales de tolerancia y respeto de parte de los miembros de la familia; y es muy claro que algunos jugaron un papel esencial, no sólo en su preparación profesional, también en la búsqueda de una nueva organización para atender a los bebés y para tender una mano a las jóvenes cuando se quedaron solas.

De este modo, la familia les brindó espacio para que transitaran del miedo, la tristeza y la culpa de ser mamás jóvenes, a sentirse afortunadas de tener a sus hijos, disfrutar con ellos e, incluso, para crear conciencia en sus familias sobre las ventajas de convivir con sus nuevos integrantes; así que quienes las favorecieron, también se vieron favorecidos por los procesos de reflexión y aprendizaje en que participaron y por la experiencia de convivir con un bebé; y este último, sin opinar en estos jaloneos, llegó como pacificador, con su nueva y lustrosa sonrisa.

Francesca: "No, pues ni me arreglo (todas ríen), así como me ven salgo, a la carrera" (G1,31,4).

Bárbara: "Véanos maestra, en el carro pintándome" (Gl,31,5).

Iliana: "No, yo peor, me vengo caminando" (Gl,31,6).

Francesca: "Sude y sude, ¿iverdad?" (G1,31,7).

Alessia: “...y sí, es cierto, a veces vengo, estoy en prácticas y me estoy durmiendo, porque, porque este, y lo peor es que no se puede uno dormir (todas se ríen), nomás (sic) estás cabeceando, pero no se duerme uno, entonces sí está muy pesado, dices, este, ya son lo último y lo único que te saca, que saca es que hay, ya estoy en octavo, ya voy a salir y es lo que te da ganas, la fuerza de diario, diario y entonces es una, diario es un este navegar de (mi 
bebé) pues, de que gracias a Dios tiene abuela, buenas abuelas que, que la quieren mucho, la cuidan..." (Gl,32,7).

Alessia: "...nunca le eché la culpa a nadie más que a mí, porque fue mi responsabilidad, de que a lo mejor si le haya echado la culpa a mi mamá o así, de mi relación, con, con mi esposo, mi novio, este, pero ahorita él ya, comprendo que no es así, que pues lo que hace uno, este, es responsabilidad de uno y más que nada pues miedo sí, sí tuve miedo, al pensar que, qué iba a pasar, después de que yo tuviera (un bebé)." (Gl,43,10).

Romina: "...a mí, llegó un punto en el que tuve que aprender a perdonar y a dejar atrás todo eso para ya no, para ya no andarlo cargando y. no sé cieda? (sic), a lo mejor si ahorita me lo ponen enfrente, sí le doy, dos, tres cachetadas, pero, digo, ya no es lo mismo que estar cargando con eso, no, no siento ya que, que deba seguirlo culpando, siento que cada quien tuvo su parte de responsabilidad y pues las cosas pasaron así y en muchos momentos me han dicho ite arrepientes?, no... (Gl,47,12).

Creo que se pueden desprender diversos aprendizajes a partir de plasmar algunos rasgos sobre las experiencias y estrategias de diálogo y cálculos que usaron las madres para conciliar sus responsabilidades y gastos familiares y escolares, pues sin duda necesitan las oportunidades que les brinda la escuela y tener una carrera universitaria. Incluso, necesitan finalizar sus procesos de formación más pronto que quienes no tienen las obligaciones de la crianza de hijos.

De igual modo para incorporar las necesidades de las mamás en las aulas y las escuelas, es preciso que seamos capaces de reconocen los diferentes retos que conllevan sus circunstancias, que hablemos más abiertamente sobre las facilidades y oportunidades que tiene postergar los embarazos y los riesgos que conlleva para los jóvenes sentirse inmunes en las prácticas sexuales. En el apartado que sigue y a modo de conclusiones, dejo algunas recomendaciones sobre cómo podemos mejorar el trato a las madres jóvenes en las aulas. 


\section{CONCLUSIONES, QUÉ LES ESPERA A LAS MADRES ADOLESCENTES Y JÓUENES EN LA ESCUELA Y DESPUÉS DE ÉSTA}

Los discursos de responsabilidad social, desarrollo sostenible y empleabilidad que permearían la educación actualidad (UNESCO, 2016), crean una gran área de oportunidad para que las universidades mexicanas incluyan mecanismos que ayuden a prevenir la maternidad temprana y reconozcan, atiendan y apoyen a las madres y padres adolescentes durante y después del embarazo. Más relevante resulta esta atención institucional porque en México y el mundo están pendientes la distribución de actividades y oportunidades entre todos, a través del consenso, la trasparencia y la búsqueda del bien común.

Mientras estas resoluciones no llegan, es posible observar que las mamás adolescentes usaron estrategias de diálogo y negociación que les permitieron no renunciar a sus hijos ni a profesionalizarse, recordarles a sus familiares, profesores y compañeros de la escuela que ellas no son una extensión de los otros, que embarazarse no implica ceder las capacidades y derechos de madres y de estudiantes.

Al mirar estas estrategias que usaron las jóvenes, es posible observar que éstas dependen más de su iniciativa personal que de los esfuerzos que se hacen desde las escuelas, pues cuando se embarazaron, adquirieron saberes para renegociar el tiempo, los roles y la distribución de tareas en la universidad y con sus familias, rehicieron el cálculo de los beneficios económicos y culturales que acarrearía su profesionalización y convencieron a los demás sobre las ventajas que tendría su activación calificada en el ámbito laboral, pues al igual que pasa con cada ser humano que accede a más oportunidades, el camino se les amplió por obtener estudios universitarios; sin embargo, fue preciso que jugaran este rol de madres para que cuestionaran el lugar en el que estaban ubicadas como protagonistas de su preparación a lo largo de la vida.

En consecuencia con lo anterior, las mamás adolescentes y jóvenes mostraron la capacidad que tienen para salir adelante con o sin sus parejas, para criar a sus hijos, disentir cuando otros a su alrededor creían ser sus 
dueños y fueron decisivas cuando se trataba de definir el estatus marital que les parecía más conveniente para sus hijos y para ellas como mujeres jóvenes e independientes.

Las posiciones de diálogo y negociación que adoptaron las mamás reflejan que dudan sobre lo que está instituido en sus escuelas y familias, que priorizan valores, tradiciones y costumbres distintas para avanzar en estos ámbitos, porque no se conforman con el lugar que implica que los demás decidan por ellas, por lo que crear nuevas brechas para transitar. Como pregona Walters (2010), podemos contar las historias de las mujeres como víctimas de los demás, o bien, además de esta postura, existe la opción de explicarlas a través de otros papeles, razones y visiones que las construyen, incluso esto opera con las representantes de una minoría cultural.

Estas visiones, diálogos y negociaciones de las mamás para sacar adelante su formación profesional y a sus hijos, contrasta con quienes miran a las mamás adolescentes y jóvenes como débiles y desvalidas, pues es preciso subrayar las responsabilidades que sobrellevaron en un proceso que es colectivo, familiar y educativo, pues cuando llegaron sus bebés, éstas propiciaron la redefinición de sus roles escolares y familiares y reorganizan el estatus, reconocimiento, tiempo y recursos económicos de quienes se encargaban o ignoraban el cuidado del nuevo ser; por lo anterior, es posible pensar en los hombres y mujeres como participantes de un mismo espacio, como colaboradores que buscan igualdad de oportunidades y de derechos familiares, profesionales y económicos.

En coincidencia con lo anterior, la discusión sobre las participaciones y oportunidades en la crianza y en la escuela, ni se reducen a ubicar a los actores como contrarios, como en la lucha constante o en relaciones de abusadores y abusados; menos todavía si responsabilizamos a un grupo de los alcances y límites del otro, pues cada actor por sí mismo tiene las mismas capacidades de explicarse y de mostrar a los demás el trato que espera, independientemente del sexo, la orientación sexual u otras preferencias. En ese sentido, dice Giddens (1995), los actores sociales saben mucho sobre las condiciones y consecuencias de lo que hacen en su rutina cotidiana, lo que a menudo se descuida son los abordajes de estos saberes. 
En este texto dejo muchos pendientes y ubico múltiples oportunidades de análisis, a penas si alcanzo a mostrar algunos rasgos de las circunstancias que vivieron las mamás adolescentes y jóvenes para terminar la escuela, por lo que en el tintero está estudiar más a fondo sus experiencias, darle voz a sus parejas, familias y otros actores de la escuela, así como explicar mejor los aspectos teóricos y metodológicos de la investigación, incorporar las alternativas que se aplican en otras universidades para esta atención y revisar otros modos de diálogo y negociación entre los implicados; incluso, una joven mamá propone que nos reunamos de nuevo para ver el después de su formación profesional; hay pues mucho más que analizar.

\section{REFERENCIAS}

ALEXANDER, J.; SMITH, P. The strong program: origins, achievements and prospects. In: HALL, J.; GRINDSTAFF, L.; LO, M. (Org.). Handbook of Cultural Sociology. Nueva York: Routledge, 2010.

BOURDIEU, P. La miseria del mundo. México: Fondo de Cultura Económica, 1999.

CROMPTON, R.; LYONETTE, C. Work-life balance in Europe. London: City University, 2005. Disponible en: <http://www.genet.ac.uk/workpapers/GeNet2005pl0.pdf>. Acceso en: 06 ago. 2013.

EUROPEAN SCIENCE FOUNDATION. Fostering Research Integrity in Europe. Europe Science Fundation, p. 1-44, 2010. Disponible en: <www.esf.org/activities/mo-fora/research-integrity.html>. Acceso en: 14 dic. 2011.

\section{GIDDENS, A. La Constitución de la Sociedad. Bases para la Teoría de la}

Estructuración. Buenos Aires: Amorrortu, 1995.

HALL, J.; GRINDSTAFF, L.; LO, M. Introduction: culture, lifeworlds, and globalization. In: HALL, J; GRINDSTAFE, L.; LO, M. (Org.). Handbook of Cultural Sociology. Nueva York: Routledge, 2010. p. 1-10.

INEGI. Estadísticas a propósito del día internacional de la mujer. México: Instituto Nacional de Estadística Geográfica e Informática, 2015. Disponible en: <http://www.inegi.org.mx/saladeprensa/aproposito/2017/mujer2017 Nal.pdf>. Acceso en: 05 jul. 2018. 
INTERNATIONAL LABOUR ORGANIZATION. Global Employment Trends for Women. Geneva: International Labour Organization, 2012. Disponible en: $<$ http://www.ilo.org/wcmsp5/groups/public/---dgreports/---dcomm/documents $/$ publication/wcms_195447.pdf\#page $=22 \& z o o m=$ auto,0,69l $>$. Acceso en: 25 jul. 2013.

LAN, P. Cultures of carework, carework across cultures. In: HALL, J.; GRINDSTAFF, L.; LO, M. (Org.). Handbook of Cultural Sociology. Nueva York: Routledge, 2010. p. 438-448.

MATURANA, H. La ciencia y la vida cotidiana: la ontología de las explicaciones científicas. In: WATZLAWICK, P.; KRIEG, P. (Comps.). El ojo del observador. Contribuciones al constructivismo. Barcelona: Gedisa, 1994. p. 157-194.

MILLS, W. La imaginación sociológica. México: Fondo de Cultura Económica, 1961.

ORGANISATION FOR ECONOMIC CO-OPERATION AND DEVELOPMENT. Employment Outlook 2016. Paris: Organisation for Economic Co-operation and Development (OECD) publishing, 2016. Disponible en: <http://www. keepeek.com/Digital-Asset-Management/oecd/employment/oecd-employment-outlook-2016_empl_outlook-2016-en\#page2l >. Acceso en: 01 sept. 2016.

PÉREZ, R.; VÍQUEZ, D. Los grupos de discussion como metodología adecuada para estudiar las cogniciones sociales. Actualidades en Psicología, v. 23, n. 110, p. 87-1 10, 2010. Disponible en: <https://revistas.ucr.ac.cr/index.php/ actualidades/article/view/12>. Acceso en: 06 jul. 2018.

POPKEWITZ, T. Paradigm and ideology in educational research. The social functions of the intellectual. USA and Canada: Routledge, 2012.

RODRÍGUEZ, G.; DE KEIJZER, B. Una aproximación etnográfica mediante visitas sucesivas. En la noche se hizo para los hombres. Sexualidad en los procesos de cortejo entre jóvenes campesinos y campesinas. México: Edamex, 2002.

SECRETARÍA DE TRABAJO Y PREVISIÓN SOCIAL. Informe Laboral. Colima, México: STPS, 2018. Disponible en: <http://www.stps.gob.mx/gobmx/estadisticas/pdf/perfiles/perfil\%20colima.pdf>. Acceso en: 05 jul. 2018. 
SIEGEL, D. Sisterhood Interrupted: From Radical Women to Girls Gone Wild. In: STADTMAN, J. (Org.). Mmo Books Review: How the personal became political. 2007. Disponible en: <http://www.mothersmovement.org/books/reviews/07/sisterhood_interrupted.html>. Acceso en: 06 ago. 2013.

UNESCO. La educación al servicio de los pueblos y el planeta: creación de futuros sostenibles para todos. Francia: Unesco, 2016. Disponible en: $<$ http://unesdoc.unesco.org/images/0024/002457/245745s.pdf>. Acceso en: 28 nov. 2017.

WALTERS, S. Lost in translation. Feminist media studies in the new millennium. In: HALL, J.; GRINDSTAFF, L.; LO, M.-C. Handbook of Cultural Sociology. Nueva York: Routledge, 2010. p. 87-96.

\section{WILLIS, P. Aprendiendo a trabajar. Cómo los chicos de la clase obrera consiguen trabajos de clase obrera. España: AKAL, 1988.}

WONG HUERTA, J. E. El rol de la educación en la movilidad social de México y Chile ¿La desigualdad por otras vías? Revista Mexicana de Investigación Educativa, v. 17, n. 52, p. 65-88, 2012. Disponible en: < http://www.comie. org. $\mathrm{mx} / \mathrm{vl} / \mathrm{revista} /$ visualizador.php?articulo=ART52003\&criterio=http://www. comie.org.mx/documentos/rmie/vl7/n052/pdf/52003.pdf>. Acceso en: 04 jul. 2012.

Recibido en 07 de marzo de 2018 Acepto en 09 de agosto de 2018

Enderezos para correspondencia: Facultad de Pedagogía de la Universidad de Colima, Josefa Ortiz de Dominguez, 64, Villa de Álvarez, 28970, Colima, México; ocsar@ucol.mxy ocsar_12@hotmail.com 